\title{
Distribution of $\alpha$-synuclein in normal human jejunum and its relations with the chemosensory and neuroendocrine system
}

\author{
Arianna Casini, ${ }^{1 *}$ Romina Mancinelli, ${ }^{1 *}$ Caterina Loredana Mammola, ${ }^{1}$ Luigi Pannarale, ${ }^{1}$ Piero Chirletti, ${ }^{2}$ \\ Paolo Onori, ${ }^{1}$ Rosa Vaccaro ${ }^{1}$ \\ ${ }^{1}$ Department of Anatomical, Histological, Forensic Medicine and Orthopedic Sciences \\ ${ }^{2}$ Department of Surgical Sciences, Sapienza University of Rome, Italy \\ *These authors share the first authorship.
}

\begin{abstract}
Alpha-synuclein $(\alpha$-syn) is a presynaptic neuronal protein and its structural alterations play an important role in the pathogenesis of neurodegenerative diseases, such as Parkinson's disease (PD). It has been originally described in the brain and aggregated $\alpha$-syn has also been found in the peripheral nerves including the enteric nervous system (ENS) of PD patients. ENS is a network of neurons and glia found in the gut wall which controls gastrointestinal function independently from the central nervous system. Moreover, two types of epithelial cells are crucial in the creation of an interface between the lumen and the ENS: they are the tuft cells and the enteroendocrine cells (EECs). In addition, the abundant enteric glial cells (EGCs) in the intestinal mucosa play a key role in controlling the intestinal epithelial barrier. Our aim was to localize and characterize the presence of $\alpha$-syn in the normal human jejunal wall. Surgical specimens of proximal jejunum were collected from patients submitted to pancreaticoduodenectomy and intestinal sections underwent immunohistochemical procedure. Alpha-syn has been found both at the level of the ENS and the epithelial cells. To characterize $\alpha$-syn immunoreactive epithelial cells, we used markers such as choline acetyltransferase (ChAT), useful for the identification of tuft cells. Then we evaluated the co-presence of $\alpha$-syn with serotonin (5-HT), expressed in EECs. Finally, we used the low-affinity nerve growth factor receptor (p75NTR), to detect peripheral EGCs. The presence of $\alpha$-syn has been demonstrated in EECs, but not in the tuft cells. Additionally, p75NTR has been highlighted in EECs of the mucosal layer and co-localized with $\alpha$-syn in EECs but not with ChAT-positive cells. These findings suggest that $\alpha$-syn could play a possible role in synaptic transmission of the ENS and may contribute to maintain the integrity of the epithelial barrier of the small intestine through EECs.
\end{abstract}

Key words: Small intestine; jejunum; tuft cells; enteroendocrine cells (EECs); $\alpha$-synuclein ( $\alpha$-syn); enteric

Correspondence: Romina Mancinelli, Dept. of Anatomical, Histological, Forensic Medicine and Orthopedics Sciences, Sapienza Università of Rome, Via Alfonso Borelli 50, 00161 Rome, Italy. Tel. +39.06.44438075. E-mail: romina.mancinelli@unitoma1.it

Contributions: AC, worked on the study design, performed morphological and immunohistochemical experiments and wrote the paper; RM, captured pictures, interpreted the results and wrote the paper, formatting the manuscript as an article; CLM, worked in the preliminary research reports about $\alpha$-synuclein, helped in the experimental and revisional aspects; LP, PO, monitored the experiments and performed a critical revision of the manuscript; PC, collected the several samples; RV, coordinated the work, interpreted the results and performed a critical revision of the manuscript.

Funding: This project received financial support from "Progetti piccoli di Ateneo 2018" of Sapienza University of Rome. 


\section{Introduction}

Alpha-synuclein ( $\alpha$-syn) is a 140 amino acid protein, belonging to the synuclein family, expressed in mammalian neurons. Alphasyn has been first cloned and isolated from the electric organ of Torpedo californica ${ }^{1}$ and localized at the level of the presynaptic nerve terminals and in the nuclear envelope. ${ }^{2}$ The normal functions of $\alpha$-syn are not entirely known, but its high concentration in presynaptic terminals suggests a role in in the maintenance of synaptic vesicles pools and in neurotransmitter release. ${ }^{3-5}$ Structural alterations of $\alpha$-syn as well as its overexpression have been related to the onset and the progression of several human neurodegenerative diseases, known as synucleinopathies. ${ }^{6-11}$ In fact, $\alpha$-syn aggregates are the main component of the Lewy bodies (Lbs), considered as pathological hallmarks of synucleinopathies. ${ }^{6,12}$ Abnormal processing of $\alpha$-syn leads to pathological changes in its binding properties with overexpression and accumulation of $\alpha$-syn resulting in compromised synaptic function and axonal transport. ${ }^{13,14}$

The jejunum is composed of repeating crypts and villi with an important niche of stem cells to sustain the rapid turnover of its epithelium. ${ }^{15}$ The intestinal stem cells (ISCs) are located at the base of the crypts and produce five different cell types: enterocytes, which are the real absorptive cells, the goblet cells, which secrete mucus into the lumen, the tuft cells, which are considered luminal sensory cells, the enteroendocrine cells (EECs), which are able to produce several hormones, and Paneth cells with antimicrobial activity. ${ }^{16}$ Some of these cell types are crucial in the interactions between the intestinal epithelium and the enteric nervous system (ENS), forming an effective interface between the lumen and nerve fibers: ${ }^{17,18}$ these are the tuft cells and EECs. In particular, the tuft cells or brush cells, characterized by a fusiform shape with apical and long microvilli, can transfer sensory signals from the lumen to other epithelial cells or neurons. ${ }^{19}$ Tuft cells express choline acetyltransferase (ChAT), responsible for acetylcholine (ACh) production, and secrete cytokines and cyclooxygenase to regulate inflammatory responses. ${ }^{20,21}$ They are part of the diffuse chemosensory system (DCS), first described by Sbarbati et al. ${ }^{22,23}$ DCS might be thought to be involved in a wide range of diseases of both the respiratory and digestive apparatuses, as well as in systemic diseases. ${ }^{24} \mathrm{~A}$ renewed interest in these tuft cells is linked to the involvement of the olfactory and digestive system by COVID19. ${ }^{25}$ Furthermore, also EECs have been linked not only to the hormone production but also to the chemosensory aspects. In fact, EECs in the mucosal layer have the apical surface open into the intestinal lumen and they can sense the luminal contents. ${ }^{26}$ EECs contains different peptides and hormones such as 5-HT and express nutrient-sensing GPCRs (G-protein-coupled receptors) regulating the local innervation. ${ }^{27,28}$ Recently, it has been shown that EECs express $\alpha$-synuclein in mouse and human intestine, discovering a direct transmission from the intestine to the brain through the vagus nerve to the dorsal motor nucleus of the vagus in the brain stem, in a retrograde manner. ${ }^{18,29}$ Remarkably, recent reports have shown that the lesions in the ENS occurred at a very early stage of the PD disease, even before the involvement of the central nervous system. For these reasons, the ENS could be critical in the pathophysiology of Parkinson's disease (PD). ${ }^{30,31}$ In such a scenario, the enteric glial reaction observed in PD may play a key role by modulating intestinal permeability as greater gut permeability has been observed in experimental parkinsonism. ${ }^{32}$ Although Lbs, as well as $\alpha$-syn pathological aggregates, have been observed throughout the autonomic nervous system projecting to the gut of patients affected by $\mathrm{PD}^{30,33-36}$ or other neurodegenerative diseases. ${ }^{31,37}$ For that reason, knowledge about the normal distribution of $\alpha$-syn could lead to a better understanding of its biological activity and its precise role in neurodegeneration, so the aim of the present study was to analyze the distribution pattern of $\alpha$-syn in the proximal tract of human normal small intestine.

\section{Materials and Methods}

All reagents were obtained from Dako-Agilent (Santa Clara, CA, USA) unless otherwise stated. The antibodies for ChAT, 5-HT and $\mathrm{p} 75 \mathrm{NT}$ receptor were obtained from Merk Millipore (Temecula, CA). The antibodies for $\alpha$-syn, together with Ultracruz aqueous mounting medium with DAPI were produced by Santa Cruz Biotechnology (Santa Cruz, CA, USA).

All the specific secondary antibodies AlexaFluor were obtained from Invitrogen, Life Technologies Ltd. (Paisley, UK).

\section{Patients and tissues}

Specimens of intestinal wall were collected from the 2 nd jejunal loop (30 $\mathrm{cm}$ from the duodenojejunal flexure). Histological samples were obtained from surgical specimens from ten patients (seven males, three females) within the age range of 45 to 84 years, submitted to a pancreaticoduodenectomy for pancreatic cancer. All patients gave informed consent to the study as part of the research investigation for gastrointestinal tract disorders.

Tissue specimens were fixed with cold $4 \%$ paraformaldehyde solution in $0.01 \mathrm{M}$ saline phosphate buffer (PBS) for 24-48 h at $+4^{\circ} \mathrm{C}$, washed, dehydrated, paraffin embedded and cut into 5-7 $\mu \mathrm{m}$ thick serial sections which were mounted on albumin coated slides.

The study has previously received ethical approval by the Institutional Review Board of the "Sapienza" University of Rome in accordance with the Declaration of Helsinki.

\section{Hematoxylin-eosin (H\&E) staining and immunohisto- chemistry}

Morphological analysis was performed using H\&E staining. Firstly, sections of human jejunum were colored with Hematoxylin solution for $10 \mathrm{~min}$ and then washed in tap water for other $10 \mathrm{~min}$. After washing, we performed the passage in Eosin for $1 \mathrm{~min}$ and deoxygenated water. Before mounting the slides with a specific mounting medium, the samples were dehydrated with ethanol of different concentration gradients and xylene.

For immunochemistry after deparaffinization, rehydration and wash in 1x phosphate buffered saline (PBS), sections were pretreated for 20 minutes at room temperature with $\mathrm{H}_{2} \mathrm{O}_{2}$, to inactivate the endogenous peroxidase activity. Then, sections were incubated with antibodies for: i) mouse anti- $\alpha$-syn (sc-58480 Santa Cruz Biotechnology, Santa Cruz, CA) 1: 250; ii) goat anti-ChAT (AB144P Merk Millipore, Temecula, CA) 1:100; or iii) rabbit anti5-HT (AB938 Merk Millipore, Temecula, CA, USA) 1: 500 overnight at $4{ }^{\circ} \mathrm{C}$. The day after, samples were rinsed twice with $1 \mathrm{x}$ PBS for $5 \mathrm{~min}$, incubated for $20 \mathrm{~min}$ at room temperature with secondary biotinylated antibody (LSAB+ System-HRP, code K0690; Dako-Agilent, Glostrup, Denmark) and then with StreptavidinHRP (LSAB+ System-HRP, code K0690, Dako-Agilent). Diaminobenzidine (DAB, Dako-Agilent) was used as substrate, and some sections were counterstained with hematoxylin. In some sections the localization of peroxidase activity was visualized by reacting the sections for $3 \mathrm{~min}$ at room temperature with a solution containing 0.04\% 3-3'diaminobenzidine tetrahydrochloride (DAB; Fluka, Buchs, Switzerland), 0.4\% nickel ammonium sulfate, and $0.003 \% \mathrm{H}_{2} \mathrm{O}_{2}$ in $0.05 \mathrm{M}$ Tris- $\mathrm{HCl}$ buffer, $\mathrm{pH} 7.6$ giving a dark blue granular precipitate. Then sections were counterstained with the Nuclear Fast Red (Kernechtrot) solution (Cat\# 368458-500G, Sigma-Aldrich, St. Louis, MO, USA) after IHC procedure. Intestinal sections were visualized and examined using the light microscope Leica Microsystems DM 4500. 


\section{Immunofluorescence}

The expression of $\alpha$-syn, ChAT, 5-HT and p75NT receptor was evaluated by immunofluorescence (IF) in human jejunum samples from normal patients. For IF, non-specific protein binding was blocked by $5 \%$ bovine serum albumin (BSA). Specimens were incubated with the previous primary antibodies and rabbit antip75NTR (AB1554, Merk Millipore, Temecula, CA). Then, specimens were washed and incubated for $1 \mathrm{~h}$ at room temperature with labeled isotype-specific secondary antibodies (AlexaFluor-488 or 594 respectively anti-mouse, anti-goat and anti-rabbit, Invitrogen, Life Technologies Ltd.) and counterstained with 4,6-diamidino-2phenylindole (DAPI) (Ultracruz aqueous mounting medium with DAPI, sc.24941, Santa Cruz Biotechnology) for visualization of cell nuclei.

\section{Image acquisition and processing}

Images were visualized using Leica Microsystems DM 4500 B Fluorescence Microscopy (Weltzlar, Germany) equipped with a JenoptikProg Res C10 Plus Videocam (Jena, Germany) or using an AX70 Provis microscope (Olympus Optical, Tokyo, Japan) with a cooled CCD digital camera (Spot, Diagnostic Instruments, Sterling Heights, MI, USA). Images were captured using the IAS 2000 software (Delta Sistemi, Rome, Italy) and saved as .tiff files. Images were digitally processed in Adobe Photoshop CS5 (San Jose, CA, USA). Only general contrast adaptations were made, and figures were not otherwise manipulated. The final figure composition was done using Microsoft Office 2020 Powerpoint software (Redmond, WA, USA).

\section{Results}

\section{Morphological analysis of the jejunal wall}

From the inner to the outer side, the wall of normal human jejunum is characteristically made up of the mucosa, submucosa, muscularis externa and serosa (Figure 1A). The mucosa contains crypts and villi, and it is formed by a single layer of epithelial columnar cells. But we can find at least other two subpopulations: i) cells with a secretory capacity, such as the goblet cells (Figure 1A, blue arrows); and ii) specialized signaling cells, such as the EECs (Figure 1B, green cells) and the tuft cells (Figure 1B, red cells). ${ }^{16}$ Since the intestinal epithelium has a rapid turnover, it also contains a niche of intestinal stem cells (ISC) that are responsible for ongoing epithelial regeneration and are located at the base of the crypts of Lieberkuhn (Figure 1A yellow arrows). ${ }^{38}$ We also took into consideration the tunica muscularis externa with the typical inner circular (CM) and outer longitudinal (LM) layers of smooth muscle, controlled by ganglion cells and nerve fibers of the submucosal (Meissner's) plexus and the myenteric (Auerbach's) plexus (Figure 1A, green arrows).

\section{$\alpha$-syn distribution in the jejunal wall}

We found a pattern of $\alpha$-syn expression consistent with previous and recent studies. It is widely expressed in the intestinal wall, in particular at the level of the enteric innervation. ${ }^{18}$ In fact, we found $\alpha$-syn immunoreactivity between the glands at the base of the jejunal epithelium (Figure 2A, black arrows). In addition, the presence of $\alpha$-syn is much evident in the ganglia of the myenteric plexus, where axons project and travel to the mucosal villi within the normal gut wall (Figure 2B, white arrows). Frequently, $\alpha$-syn not only was present in the ganglion with dendritic branches of the
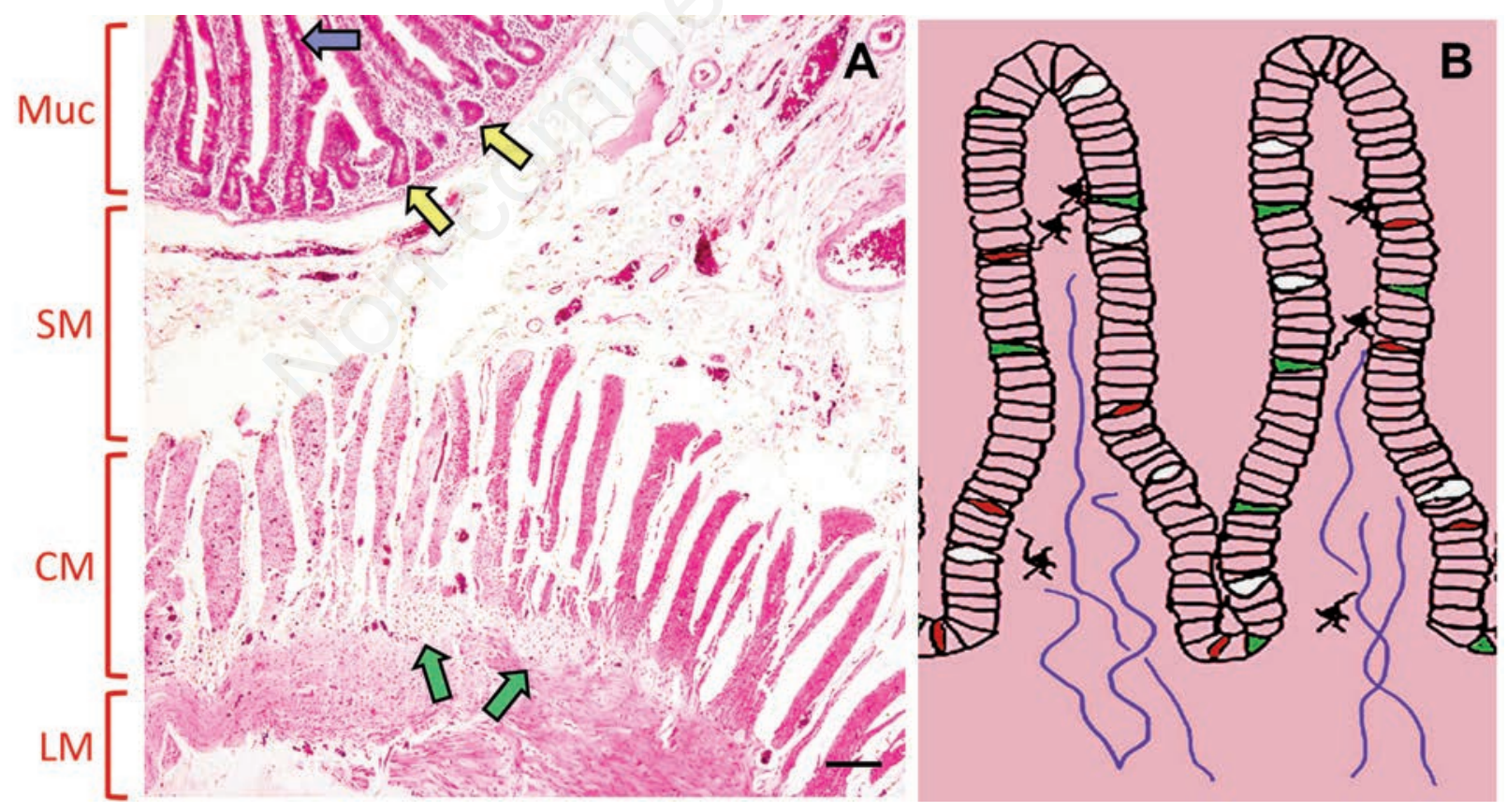

Figure 1. A) Morphological aspects of a normal human jejunum through H\&E routinely staining; in this representative picture is shown the typical aspect of the jejunal wall with the mucosa (Muc), submucosa (SM), muscularis with the inner circular layer (CM) and the outer longitudinal layer (LM); in the mucosa are visible plentiful enterocytes and globet cells (blue arrows); at the base of the crypts of Lieberkuhn (yellow arrows) there are intestinal stem cells niche; in the muscularis, between the double layer are present characteristic ganglia of Auerbach's plexus (green arrows); original magnification: 10x; scale bar :100 $\mu \mathrm{m}$. B) Schematic drawings of jejunal mucosa; both nerve fibers and EGCs are in close contact with epithelial cells; green, EECs; red, tuft cells; white, globet cells; black, EGCs; blue: nerve fibers. 
intrinsic neurons, but also encircled it in a perfect way, as shown in the IF of Figure 2B. $\alpha$-Syn is not only present in the enteric nerves, but also in the epithelial mucosal cells. In addition, we found that $\alpha$-syn is not expressed by the enterocytes.

\section{$\alpha$-syn and ChAT expression in the jejunal epithelium}

To determine if $\alpha$-syn is present in other mucosal subpopula- tions, we have used specific markers. The first one tested, was ChAT, the enzyme choline acetyltransferase important to produce ACh and broadly utilized as a marker for the cholinergic tuft cells. ${ }^{39}$ Through IHC, we have analyzed the expression of ChAT in normal jejunal epithelium, and we have localized the presence of the enzyme at the level of tuft cells (Figure 3A, red arrows). Then, using a double IF, we have studied the expression of ChAT together with $\alpha$-syn to find
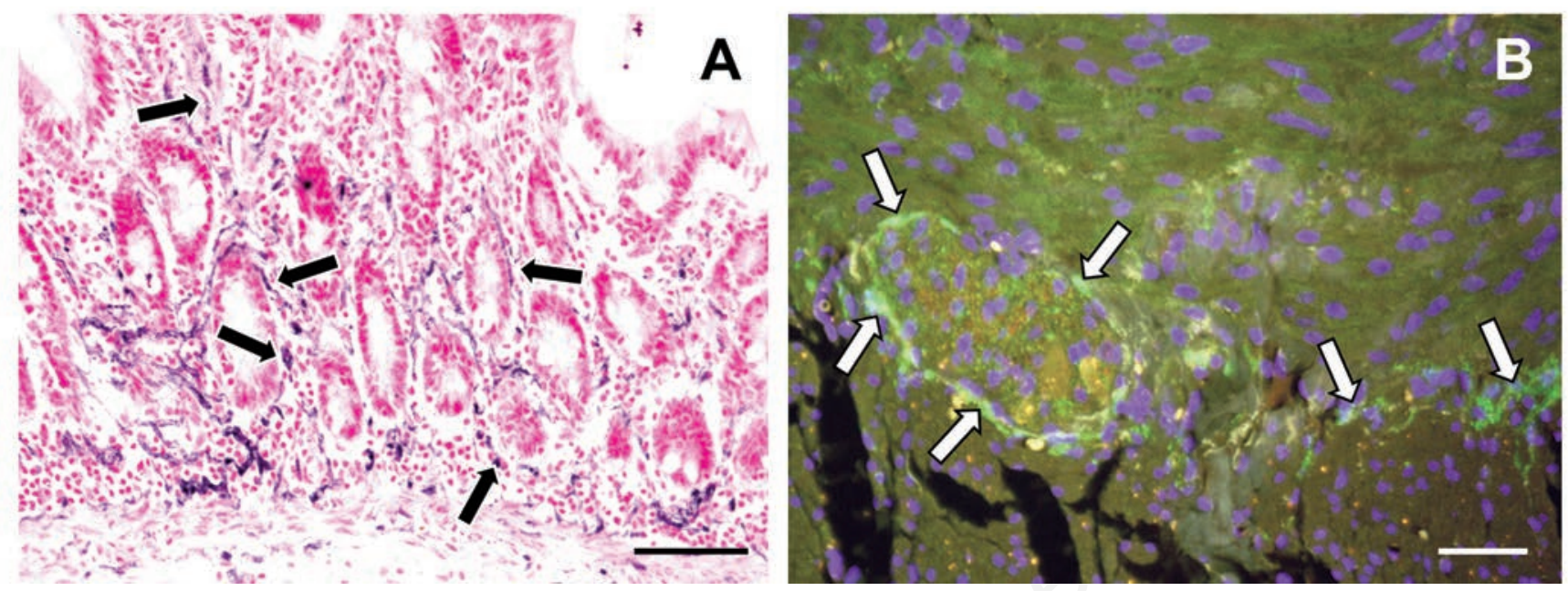

Figure 2. Immunohistochemistry (A) and immunofluorescence (B) in paraffin sections of normal human jejunum showing the typical expression of $\alpha$-syn. A) $\alpha$-syn varicose nerve fibers are evident in dark blue, and it are widespread in the glands at the base of the villi (black arrows); original magnification: 10x; scale bar: $100 \mu \mathrm{m}$. B) $\alpha$-syn is stained with a green fluorochrome at the level of a myenteric ganglion, and it continues in the chain of connection between ganglia (white arrows); original magnification: 10x; scale bar: $50 \mu \mathrm{m}$.
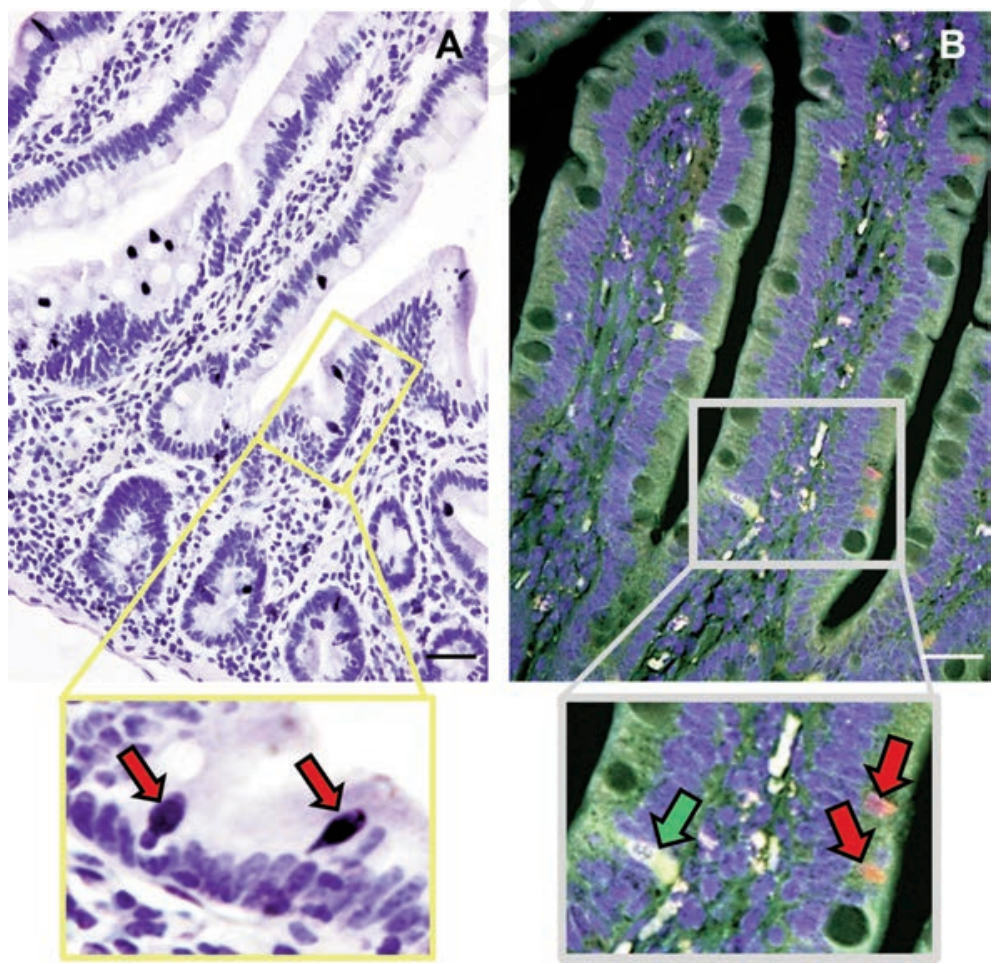

Figure 3. A) Representative immunoreaction of normal jejunal tissue for the presence of ChAT (dark blue); the expression of ChAT has been widely studied on tuft cells, that are considered part of the non-neuronal cholinergic system; for that reason, the rare cells stained in dark blue in mucosal epithelium are tuft cells; in the high-magnification field, the positive cells are more evident (red arrows); original magnification: 10x; scale bar: $50 \mu \mathrm{m}$. B) Double immunofluorescence to identify the expressions of $\alpha$-syn and ChAT; green arrows indicate scattered $\alpha$-syn-positive cells, whereas red arrows point ChAT-positive cells; they do not co-localize in the same epithelial cell, meaning that different mucosal cells express differentially $\alpha$-syn and ChAT; original magnification: 10x; scale bar: $50 \mu \mathrm{m}$. 
that the two antibodies did not co-localize in the same epithelial cells (Figure 3B). In detail, we have confirmed the immunoreaction of ChAT at the level of tuft cells in normal human jejunum (Figure 3B, red color), while the expression of $\alpha$-syn was at the level of different occasional mucosal cells (Figure 3B, green color). For that reason, the next step has been to discover which type of cells express $\alpha$-syn.

\section{Presence of $\alpha$-syn in EECs and co-localization with p75NTR}

Having established the different presence of $\alpha$-syn compared to ChAT in the mucosal tunica, we have used 5-HT, one of the typical markers of EECs (28). First, we have tested the antibody through IHC, and we have localized 5-HT-containing enterochromaffin cells, which represent the enteroendocrine subpopulation of the mucosal layer (Figure 4A, red arrows). Similarly, to the previous experiments, we have performed a double IF to co-localize $\alpha$-syn and 5-HT. As shown in human duodenum, ${ }^{18}$ also in normal human jejunum $\alpha$-syn is expressed in EECs (Figure 4B, yellow arrows). In fact, the IF has shown a co-localization with a yellow color in the cytoplasm of same specific cells. Moreover, we have identified a higher expression of $\alpha$-syn at the base of the EECs, where the terminals of the $\alpha$-syn-positive enteric nerve are present and could communicate and transmit information in the mucosal layer. To confirm that a relationship between the ENS and the epithelial layer through the EECs exists, we have continued to evaluate another nervous marker: the neurotrophin receptor p75 (p75NTR). In particular, since nerve growth factor (NGF) plays an important role in the intestinal pathophysiology, such as in barrier function and mobility ${ }^{40}$ we have investigated a possible cross talk between $\alpha$-syn and NGF at the level of EECs. Through another double IF, we have displayed a co-staining of $\alpha$-syn and p75NTR at the level of the EECs (Figure 5, yellow arrows). Also in these experiments, we have observed the main expression of $\alpha$-syn at the base of the cells, closer to the internal part of the villus, where enteric neuronal branches $\alpha$-syn-positive are present (small green arrows). In fact, with this double IF we found several portions of the EGCs positive independently for $\alpha$-syn (Figure 5, small green arrows) and p75NTR (Figure 5, small red arrows) inside the villi. In the present figure, we can appreciate a long branch $\alpha$-syn-positive that from the inner of the villus reaches an EEC (red oval), to confirm the important role of $\alpha$-syn in the communications between ENS with the EECs.

\section{Presence of ChAT in tuft cells without a co-localization with p75NTR}

To complete the study and to exclude or include even a probable participation of tuft cells in the crosstalk with NGF, we colocalized ChAT with p75NTR. But, in normal human jejunum, we found that the tuft cells did not express the NGF receptor (Figure 6 ). The presence of ChAT was confirmed in the tuft cells (Figure 6 , red arrows), but in these cells we did not find a co-localization with p75NTR, excluding the possible communication of the enteric innervation with tuft cells both through $\alpha$-syn and NGF. Whereas we found other cells that stained in green and were positive for p75NTR (Figure 6, green arrows).
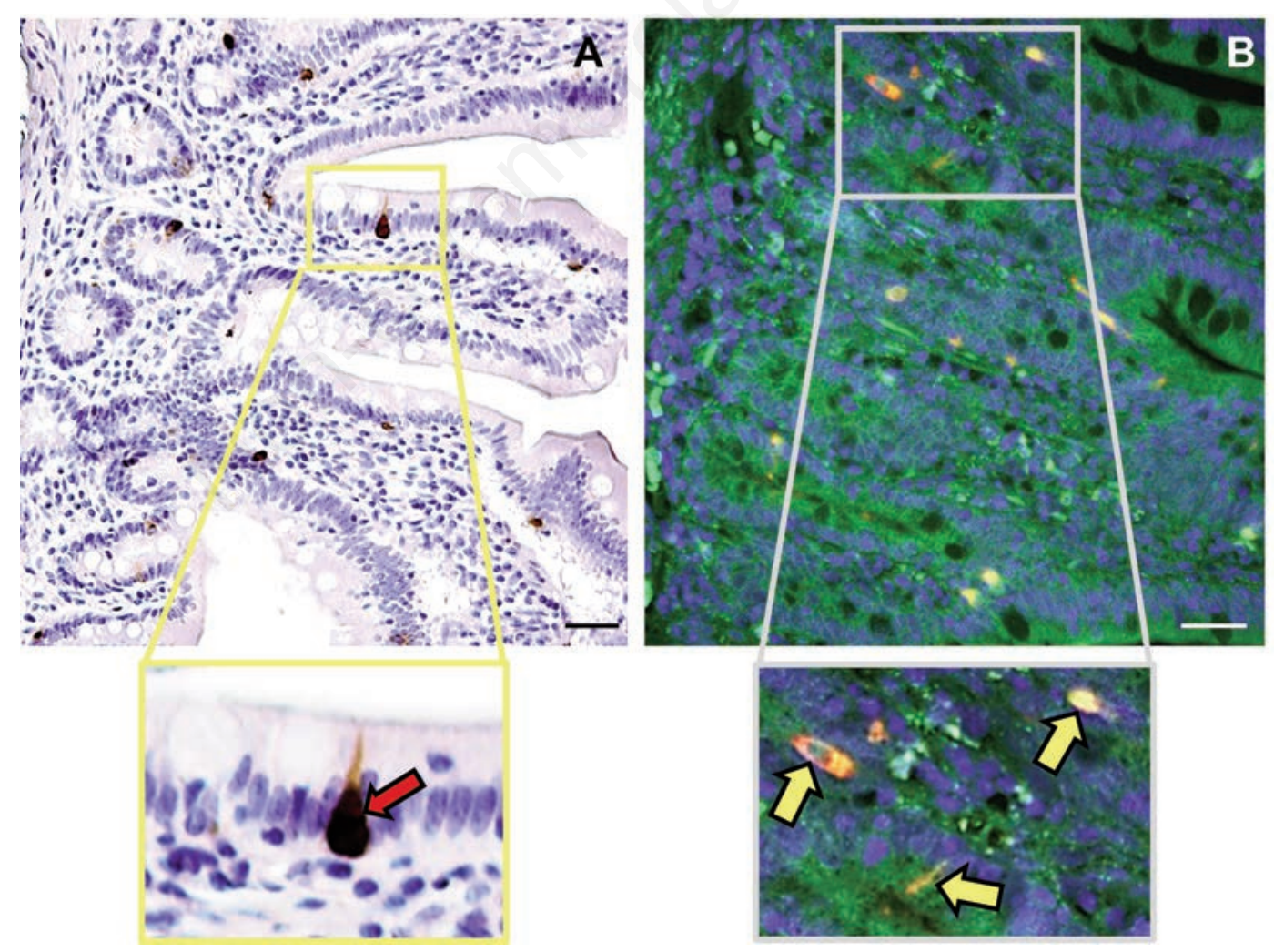

Figure 4. A) IHC to evaluate the presence of 5-HT and its distribution in secreting EECs; paraffin section of human jejunum shows immunoreactive EEC in brown along the mucosal layer (red arrows) with different aspects depending on the typical tridimensional shape of EEC cells; original magnification: 10x; scale bar: $50 \mu \mathrm{m}$. B) Representative double IF for $\alpha$-syn (in green) and 5-HT (in red); the staining displays co-localization different cells; these yellow cells may represent the enteroendocrine compartment of the small intestine in relation with the nervous control of the jejunum; original magnification: 10x; scale bar: $50 \mu \mathrm{m}$. 


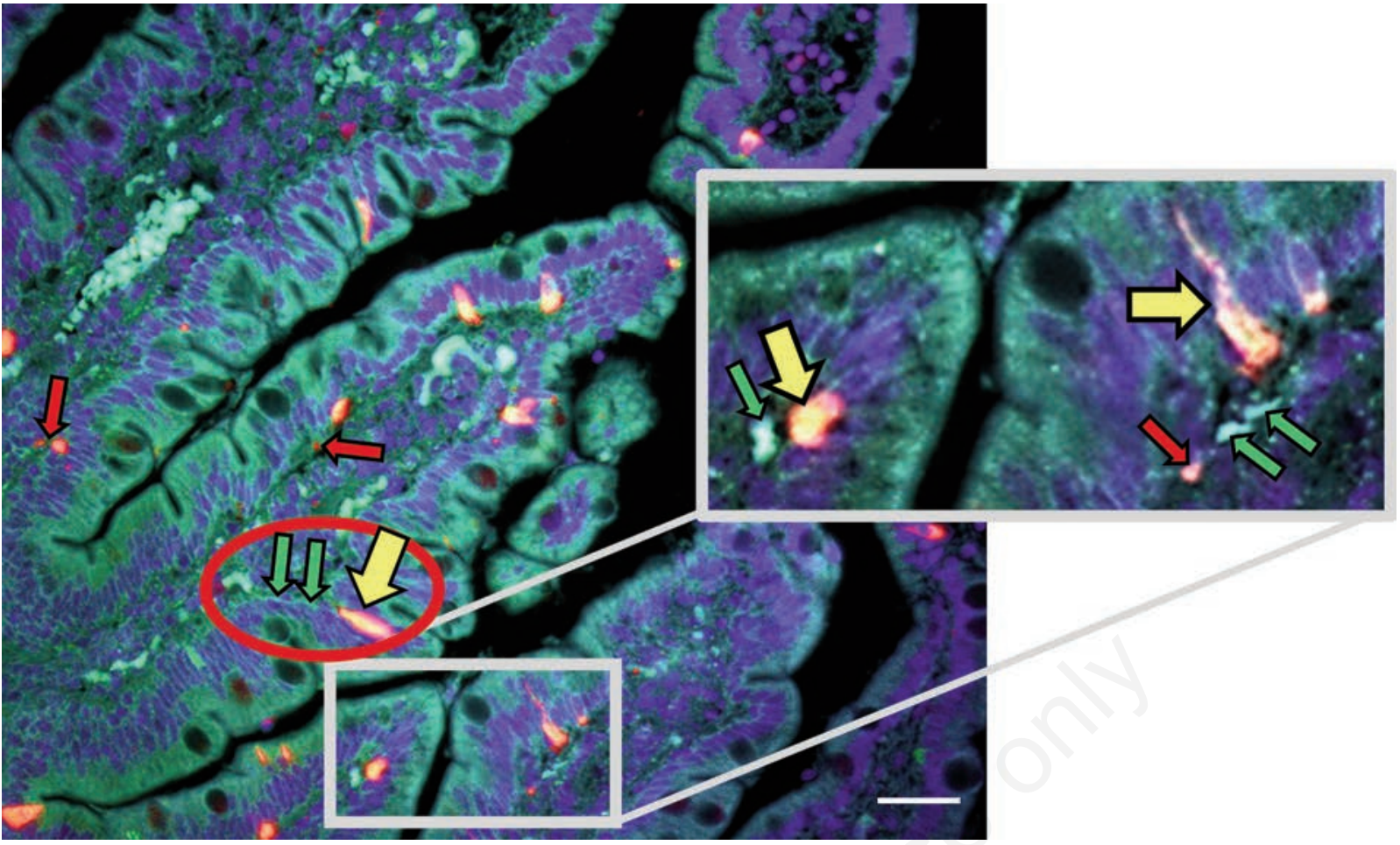

Figure 5. A cross section of human jejunum in which $\alpha$-syn (in green) and p75 NTR (in red) are co-localized at the level of EEC cells (yellow arrows). The expression of $\alpha$-syn (green arrows) is also widespread at the base of mucosal layer. In the grey box, at the base of the co-stained cells is evident the green $\alpha$-syn to support the regulatory function of EEC cells in a normal jejunum between the lumen and the ENS. In the red oval, it is clearly represented a fiber to connect the internal part of the villus with the epithelial cells. A green $\alpha$-syn-positive branch (small green arrows) runs from the inner side of the villus to the base of a yellow ECC, positive both for $\alpha$-syn and p75NTR, like an electric wire to its lamp; original magnification: $20 x$; scale bar: $50 \mu \mathrm{m}$.

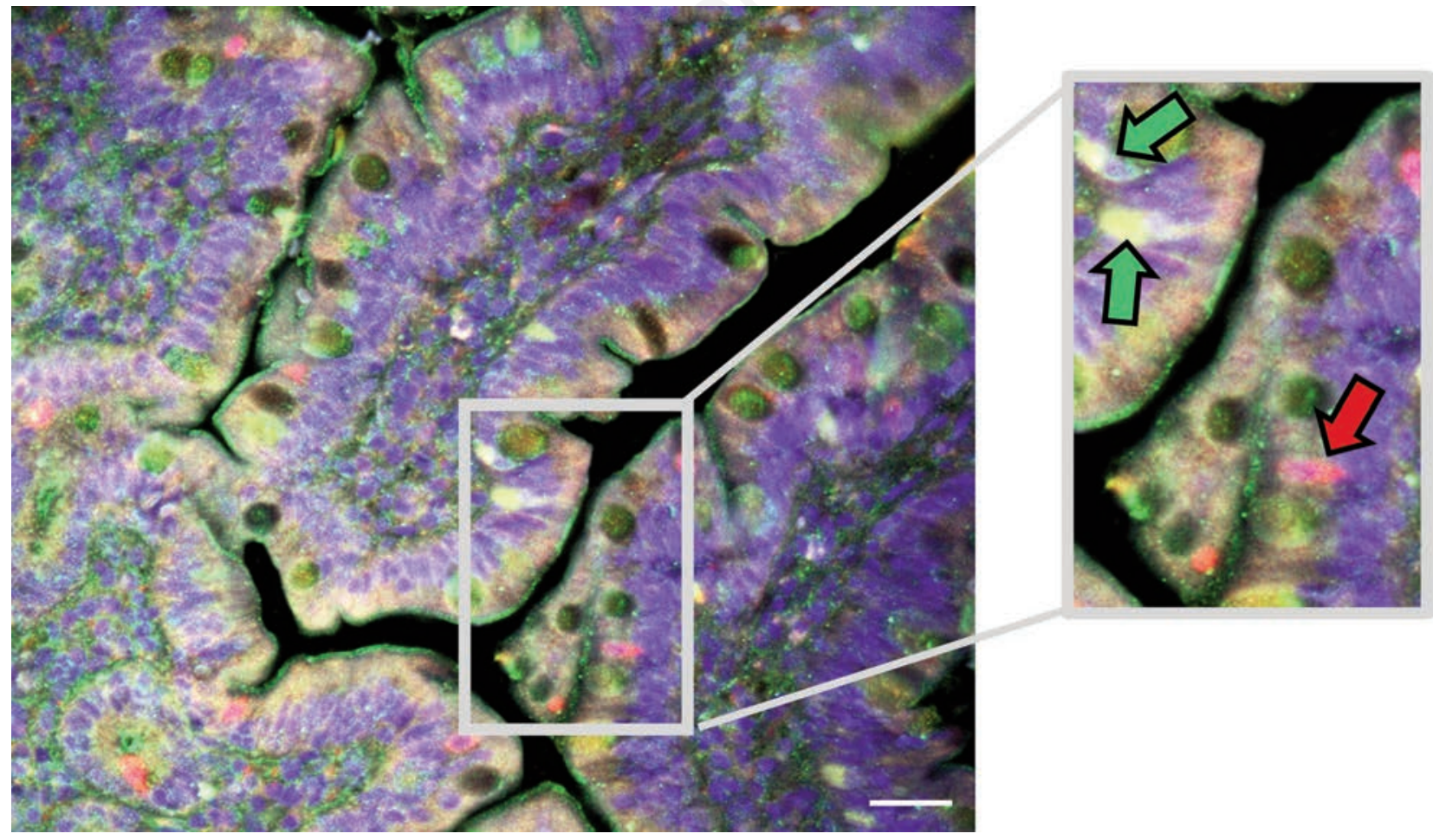

Figure 6. A double IF for p75NTR (in green) and ChAT (in red) to show their different localization. The expression of ChAT is always at the level of the tuft cells, evident in the red cells. Whereas the low-affinity NGF receptor is present in other cells and at the base of the epithelium (green arrows). This picture endorses the previous data showing that the possible communications between the intestinal lumen and the ENS is managed by the $\alpha$-syn-positive EECs. Tuft cells could act and regulate the communications between ENS and intestinal lumen through another pathway; original magnification: 20x; scale bar: $50 \mu \mathrm{m}$. 


\section{Discussion}

In the present study, we have investigated the distribution of $\alpha$ syn in the human normal jejunal wall focusing on the relations between some specific epithelial cells, such as EECs and tuft cells, with enteric nerve fibers and EGCs. Our first results have confirmed the typical localization of $\alpha$-syn between the glands and in the ganglia of the submucosal plexus.

Additionally, we have shown the presence of scattered EECs expressing $\alpha$-syn which colocalize with 5 -HT in normal human jejunum. But we did not find a similar situation in ChAT-positive tuft cells. Then, we have co-localized p75NTR in $\alpha$-syn- positive EECs but not in ChAT-positive tuft cells. The gastrointestinal epithelium contains sensory cells, such as tuft and endocrine cells, which can transport luminal signals to the neighboring cells or to the nerve terminals of the ENS. In fact, enteric nerves cannot reach the intestinal lumen and, they do not have a direct contact with the intestinal content but through these sensory cells. ${ }^{18,41}$ In detail, 5HT containing EECs are the most abundant type of EEC in the intestine. ${ }^{42-45}$ They were discovered to possess many neuron-like features including neurofilament-containing axon-like processes called neuropods and neurotrophin receptors, pre- and post-synaptic proteins. ${ }^{46}$ Expression of synaptic proteins raised the possibility that EECs meet nerves, connecting the gut lumen with the nervous system. ${ }^{26}$ In addition, production and distribution of EECs are stricktly linked to the inflammatory process, mediating the connections between the immune, endocrine and nervous systems in the gastrointestinal tract. In fact, colonic inflammation is crucially correlated to changes in the expression of $\alpha-s y n .{ }^{47}$ Our data are consistent with other articles, where the presence of $\alpha$-syn has been discovered in the basal surface of the EECs suggesting that these cells diffused throughout the mucosal lining can sense luminal contents and also connect to enteric nerves. ${ }^{18}$ By virtue of their location at the interface of the gut lumen and enteric nerves, EECs may be subject to pathogen or toxin exposure that could affect $\alpha$ syn. ${ }^{18} \alpha$-syn should misfold in EECs, its transmission to $\alpha$-syn-containing enteric neurons could be the first step in a prion-like cascade leading to PD. The other intestinal sensory population is represented by the cholinergic tuft cells. ${ }^{39,48}$ Current evidence demonstrated that tuft cells derived ACh contribute to maintain epithelial homeostasis, modulating airway remodeling, regulating reflexes, promoting muscle constriction, inducing neurogenic inflammation, initiating carcinogenesis, and producing ATP, but their mechanism remain still not completely elucidated. ${ }^{39}$ In fact, ChAT-immunoreactive tuft cells are separate from $\alpha$-syn -positive EECs, as our results have shown. Both cellular populations seem to be involved in the same functions and activities, but apparently in different ways, and our interest has been to investigate a possible connection between these different type of cells with the ENS.

The intestinal epithelial barrier (IEB) serves as the first boundary of defense between the blood circulation and the luminal environment, blocking the passage of noxious substances. ${ }^{49,50}$ It consists of a continuous monolayer of proliferating and differentiating intestinal epithelial cells, maintained together by intercellular junctional complexes. ${ }^{51-53}$ The abundant EGCs in the intestinal mucosa play a key role in controlling IEB.$^{54}$ In fact, at the base of the intestinal epithelial cells we have a population of astrocyte-like cells that corresponds to the enteric glia. They can be considered as astrocytes of the central nervous system both for morphological aspects and for the expression of specific markers. ${ }^{55}$ In our study, we found sparse EGCs in the mucosal layer, positive for p75NTR, these cells are in close contact with the $\alpha$-syn positive and 5-HTpositive cells. In particular, we have displayed the co-localization of $\alpha$-syn and p75NTR at the level of the EECs, while cholinergic tuft cells did not express the NGF receptor. EGCs serve a function of structural support to enteric neurons and to constitute large communication networks to integrate neurons and other cells in the gut. ${ }^{56}$ EGCs may play a crucial role in the regulation of epithelial cell proliferation and gut motility. In fact, mucosal EGCs are suggested to be involved in the maintenance of intestinal epithelial barrier, and alterations of their activity occur in different disorders, including PD. ${ }^{57}$ Even if it is so, the underlying mechanisms of how EGCs may influence epithelial cells and the maintenance of intestinal epithelial barrier function remain undefined. ${ }^{58}$ Through our results, we can speculate that the $\alpha$-syn positive EECs may act as a possible chemosensory link between mucosal EGCs and the intestinal lumen, inducing changes in the intestinal homeostasis at the base of the gut disorders. In the end, our findings show three protagonists of the intestinal changes, anatomically localized in strategic positions: EECs, EGCs and ENS. They play a fundamental role in the pathological staging of gastrointestinal diseases, where the environmental factors can cross the intestinal barrier through the EECs, start the process of enteric neurodegeneration through the EGCs and can spread from the gut to the brain through the ENS. All these activities may be in part regulated through $\alpha$ syn, as confirmed in some pathological studies with postmortem tissues of the brain and peripheral nervous structures, where it has been found that pathological a-syn nucleation and aggregation may occur in the enteric neurons of the gastrointestinal tract and can propagate from the intestine to the central nervous system. ${ }^{30,59-61}$

\section{Acknowledgments}

We thank Francesca Bottacchiari and Ludovica Garro, Sapienza University of Rome, for their assistance with the revision of the manuscript and for their comments that improved the present article.

\section{References}

1. Carlson SS, Kelly RB. An antiserum specific for cholinergic synaptic vesicles from electric organ. J Cell Biol 1980;87:98103.

2. Maroteaux L, Campanelli JT, Scheller RH. Synuclein: a neuron-specific protein localized to the nucleus and presynaptic nerve terminal. J Neurosci 1988;8:2804-15.

3. Larsen KE, Schmitz Y, Troyer MD, Mosharov E, Dietrich P, Quazi AZ, et al. Alpha-synuclein overexpression in PC12 and chromaffin cells impairs catecholamine release by interfering with a late step in exocytosis. J Neurosci 2006;26:11915-22.

4. Gitler AD, Shorter J. Prime time for alpha-synuclein. J Neurosci 2007;27:2433-4.

5. Burre J, Sharma M, Tsetsenis T, Buchman V, Etherton MR, Sudhof TC. Alpha-synuclein promotes SNARE-complex assembly in vivo and in vitro. Science 2010;329:1663-7.

6. Spillantini MG, Schmidt ML, Lee VM, Trojanowski JQ, Jakes R, Goedert M. Alpha-synuclein in Lewy bodies. Nature 1997;388:839-40.

7. Martin LJ, Pan Y, Price AC, Sterling W, Copeland NG, Jenkins NA, et al. Parkinson's disease alpha-synuclein transgenic mice develop neuronal mitochondrial degeneration and cell death. J Neurosci 2006;26:41-50.

8. Al-Chalabi A, Durr A, Wood NW, Parkinson MH, Camuzat A, Hulot JS, et al. Genetic variants of the alpha-synuclein gene SNCA are associated with multiple system atrophy. PLoS One 2009;4:e7114.

9. Scholz SW, Houlden H, Schulte C, Sharma M, Li A, Berg D, 
et al. SNCA variants are associated with increased risk for multiple system atrophy. Ann Neurol 2009;65:610-4.

10. Jellinger KA. Interaction between pathogenic proteins in neurodegenerative disorders. J Cell Mol Med 2012;16:1166-83.

11. Adamkov M, Plank L. [Prognostic relevance of histopathologic subtyping of nodular-sclerotic types of Hodgkin's disease].[Article in Slovak]. Bratisl Med J 1990;91:433-6.

12. Arima K, Ueda K, Sunohara N, Hirai S, Izumiyama Y, Tonozuka-Uehara $\mathrm{H}$, et al. Immunoelectron-microscopic demonstration of NACP/alpha-synuclein-epitopes on the filamentous component of Lewy bodies in Parkinson's disease and in dementia with Lewy bodies. Brain Res 1998;808:93-100.

13. Galvin JE, Uryu K, Lee VM, Trojanowski JQ. Axon pathology in Parkinson's disease and Lewy body dementia hippocampus contains alpha-, beta-, and gamma-synuclein. Proc Natl Acad Sci USA 1999;96:13450-5.

14. Chua CE, Tang BL. alpha-synuclein and Parkinson's disease: the first roadblock. J Cell Mol Med 2006;10:837-46.

15. Lema I, Araujo JR, Rolhion N, Demignot S. Jejunum: The understudied meeting place of dietary lipids and the microbiota. Biochimie 2020;178:124-36.

16. Walsh KT, Zemper AE. The enteric nervous system for epithelial researchers: Basic anatomy, techniques, and interactions with the epithelium. Cell Mol Gastroenterol Hepatol 2019;8:369-78.

17. Morroni M, Cangiotti AM, Cinti S. Brush cells in the human duodenojejunal junction: an ultrastructural study. J Anat 2007;211:125-31.

18. Chandra R, Hiniker A, Kuo YM, Nussbaum RL, Liddle RA. alpha-synuclein in gut endocrine cells and its implications for Parkinson's disease. JCI Insight 2017;2:e92295.

19. Sato A. Tuft cells. Anat Sci Int 2007;82:187-99.

20. Hayakawa Y, Sakitani K, Konishi M, Asfaha S, Niikura R, Tomita H, et al. Nerve Growth factor promotes gastric tumorigenesis through aberrant cholinergic signaling. Cancer Cell 2017;31:21-34.

21. von Moltke J, Ji M, Liang HE, Locksley RM. Tuft-cell-derived IL-25 regulates an intestinal ILC2-epithelial response circuit. Nature 2016;529:221-5.

22. Sbarbati A, Bramanti P, Benati D, Merigo F. The diffuse chemosensory system: exploring the iceberg toward the definition of functional roles. Prog Neurobiol 2010;91:77-89.

23. Sbarbati A, Crescimanno C, Benati D, Osculati F. Solitary chemosensory cells in the developing chemoreceptorial epithelium of the vallate papilla. J Neurocytol 1998;27:631-5.

24. Sbarbati A, Osculati F. The taste cell-related diffuse chemosensory system. Prog Neurobiol 2005;75:295-307.

25. Veronese S, Merigo F, Sbarbati A. Did we forget the diffuse chemosensory system when studying COVID-19? Immunol Lett 2021;231:26-7.

26. Bohorquez DV, Shahid RA, Erdmann A, Kreger AM, Wang Y, Calakos N, et al. Neuroepithelial circuit formed by innervation of sensory enteroendocrine cells. J Clin Invest 2015;125:782-6.

27. Ronnestad I, Akiba Y, Kaji I, Kaunitz JD. Duodenal luminal nutrient sensing. Curr Opin Pharmacol 2014;19:67-75.

28. Akiba Y, Hashimoto S, Kaunitz JD. Duodenal chemosensory system: enterocytes, enteroendocrine cells, and tuft cells. Curr Opin Gastroenterol 2020;36:501-8.

29. Holmqvist S, Chutna O, Bousset L, Aldrin-Kirk P, Li W, Bjorklund $\mathrm{T}$, et al. Direct evidence of Parkinson pathology spread from the gastrointestinal tract to the brain in rats. Acta Neuropathol 2014;128:805-20.

30. Braak H, de Vos RA, Bohl J, Del Tredici K. Gastric alphasynuclein immunoreactive inclusions in Meissner's and Auerbach's plexuses in cases staged for Parkinson's disease- related brain pathology. Neurosci Lett 2006;396:67-72.

31. Wakabayashi K, Mori F, Tanji K, Orimo S, Takahashi H. Involvement of the peripheral nervous system in synucleinopathies, tauopathies and other neurodegenerative proteinopathies of the brain. Acta Neuropathol 2010;120:1-12.

32. Kelly LP, Carvey PM, Keshavarzian A, Shannon KM, Shaikh M, Bakay RA, et al. Progression of intestinal permeability changes and alpha-synuclein expression in a mouse model of Parkinson's disease. Mov Disord 2014;29:999-1009.

33. den HJW, Bethlem J. The distribution of Lewy bodies in the central and autonomic nervous systems in idiopathic paralysis agitans. J Neurol Neurosurg Psychiatry 1960;23:283-90.

34. Wakabayashi K, Takahashi H, Takeda S, Ohama E, Ikuta F. Parkinson's disease: the presence of Lewy bodies in Auerbach's and Meissner's plexuses. Acta Neuropathol 1988;76:217-21.

35. Beach TG, Adler CH, Sue LI, Vedders L, Lue L, White Iii CL, et al. Multi-organ distribution of phosphorylated alpha-synuclein histopathology in subjects with Lewy body disorders. Acta Neuropathol 2010;119:689-702.

36. Devos D, Lebouvier T, Lardeux B, Biraud M, Rouaud T, Pouclet $\mathrm{H}$, et al. Colonic inflammation in Parkinson's disease. Neurobiol Dis 2013;50:42-8.

37. Pouclet H, Lebouvier T, Coron E, Rouaud T, Flamant M, Toulgoat F, et al. Analysis of colonic alpha-synuclein pathology in multiple system atrophy. Parkinsonism Relat Disord 2012;18:893-5.

38. Sailaja BS, He XC, Li L. The regulatory niche of intestinal stem cells. J Physiol. 2016;594:4827-36.

39. Schutz B, Ruppert AL, Strobel O, Lazarus M, Urade Y, Buchler MW, et al. Distribution pattern and molecular signature of cholinergic tuft cells in human gastro-intestinal and pancreatic-biliary tract. Sci Rep 2019;9:17466.

40. Stanzel RD, Lourenssen S, Blennerhassett MG. Inflammation causes expression of NGF in epithelial cells of the rat colon. Exp Neurol 2008;211:203-13.

41. Del Colle A, Israelyan N, Gross Margolis K. Novel aspects of enteric serotonergic signaling in health and brain-gut disease. Am J Physiol Gastrointest Liver Physiol 2020;318:G130-43.

42. Nozawa K, Kawabata-Shoda E, Doihara H, Kojima R, Okada $\mathrm{H}$, Mochizuki S, et al. TRPA1 regulates gastrointestinal motility through serotonin release from enterochromaffin cells. Proc Natl Acad Sci USA 2009;106:3408-13.

43. Reynaud Y, Fakhry J, Fothergill L, Callaghan B, Ringuet M, Hunne B, et al. The chemical coding of 5-hydroxytryptamine containing enteroendocrine cells in the mouse gastrointestinal tract. Cell Tissue Res 2016;364:489-97.

44. Diwakarla S, Fothergill LJ, Fakhry J, Callaghan B, Furness JB. Heterogeneity of enterochromaffin cells within the gastrointestinal tract. Neurogastroenterol Motil 2017;29:e13101.

45. Koo A, Fothergill LJ, Kuramoto H, Furness JB. 5-HT containing enteroendocrine cells characterised by morphologies, patterns of hormone co-expression, and relationships with nerve fibres in the mouse gastrointestinal tract. Histochem Cell Biol 2021;155:623-36

46. Bohorquez DV, Samsa LA, Roholt A, Medicetty S, Chandra R, Liddle RA. An enteroendocrine cell-enteric glia connection revealed by 3D electron microscopy. PLoS One 2014;9:e89881.

47. Resnikoff H, Metzger JM, Lopez M, Bondarenko V, Mejia A, Simmons HA, et al. Colonic inflammation affects myenteric alpha-synuclein in nonhuman primates. J Inflamm Res 2019;12:113-26.

48. Schneider C, O'Leary CE, Locksley RM. Regulation of immune responses by tuft cells. Nat Rev Immunol 
2019;19:584-93.

49. Fasano A, Shea-Donohue T. Mechanisms of disease: the role of intestinal barrier function in the pathogenesis of gastrointestinal autoimmune diseases. Nat Clin Pract Gastroenterol Hepatol 2005;2:416-22.

50. Clairembault T, Leclair-Visonneau L, Neunlist M, Derkinderen P. Enteric glial cells: new players in Parkinson's disease? Mov Disord 2015;30:494-8.

51. Yu YB, Li YQ. Enteric glial cells and their role in the intestinal epithelial barrier. World J Gastroenterol 2014;20:11273-80.

52. Latorre R, Sternini C, De Giorgio R, Greenwood-Van Meerveld B. Enteroendocrine cells: a review of their role in brain-gut communication. Neurogastroenterol Motil 2016;28:620-30.

53. Middelhoff M, Westphalen CB, Hayakawa Y, Yan KS, Gershon MD, Wang TC, et al. Dclk1-expressing tuft cells: critical modulators of the intestinal niche? Am J Physiol Gastrointest Liver Physiol 2017;313:G285-99.

54. Van Landeghem L, Chevalier J, Mahe MM, Wedel T, Urvil P, Derkinderen P, et al. Enteric glia promote intestinal mucosal healing via activation of focal adhesion kinase and release of proEGF. Am J Physiol Gastrointest Liver Physiol 2011;300: G976-87.
55. Grundmann D, Loris E, Maas-Omlor S, Huang W, Scheller A, Kirchhoff F, et al. Enteric glia: S100, GFAP, and beyond. Anat Rec (Hoboken) 2019;302:1333-44.

56. Grubisic V, Gulbransen BD. Enteric glia: the most alimentary of all glia. J Physiol 2017;595:557-70.

57. Fornai M, van den Wijngaard RM, Antonioli L, Pellegrini C, Blandizzi C, de Jonge WJ. Neuronal regulation of intestinal immune functions in health and disease. Neurogastroenterol Motil 2018;30:e13406.

58. Meir M, Kannapin F, Diefenbacher M, Ghoreishi Y, Kollmann $\mathrm{C}$, Flemming $\mathrm{S}$, et al. Intestinal epithelial barrier maturation by enteric glial cells is GDNF-dependent. Int $\mathrm{J}$ Mol Sci 2021;22:1887.

59. Braak H, Rub U, Gai WP, Del Tredici K. Idiopathic Parkinson's disease: possible routes by which vulnerable neuronal types may be subject to neuroinvasion by an unknown pathogen. J Neural Transm (Vienna) 2003;110:517-36.

60. von Boyen GB, Schulte N, Pfluger C, Spaniol U, Hartmann C, Steinkamp M. Distribution of enteric glia and GDNF during gut inflammation. BMC Gastroenterol 2011;11:3.

61. Del Tredici K, Braak H. Review: Sporadic Parkinson's disease: development and distribution of alpha-synuclein pathology. Neuropathol Appl Neurobiol 2016;42:33-50.

Received for publication: 30 July 2021. Accepted for publication: 8 September 2021.

This work is licensed under a Creative Commons Attribution-NonCommercial 4.0 International License (CC BY-NC 4.0).

(C) Copyright: the Author(s), 2021

Licensee PAGEPress, Italy

European Journal of Histochemistry 2021; 65:3310

doi:10.4081/ejh.2021.3310 